OPEN ACCESS

Edited by:

Stefan de Folter,

Center for Research and Advanced

Studies of the National Polytechnic Institute (CINVESTAV), Mexico

Reviewed by:

David Smyth,

Monash University, Australia

Toshiro Ito,

Nara Institute of Science

and Technology, Japan

*Correspondence:

Eunkyoo Oh

eoh@jnu.ac.kr

tThese authors have contributed equally to this work.

Specialty section:

This article was submitted to Plant Evolution and Development, a section of the journal Frontiers in Plant Science

Received: 23 May 2017 Accepted: 13 July 2017

Published: 25 July 2017

Citation: Hwang G, Zhu J-Y, Lee YK, Kim S, Nguyen TT, Kim J and Oh E (2017) PIF4 Promotes Expression of LNG1 and LNG2 to Induce Thermomorphogenic Growth in Arabidopsis.

Front. Plant Sci. 8:1320. doi: 10.3389/fpls.2017.01320

\section{PIF4 Promotes Expression of LNG1 and LNG2 to Induce Thermomorphogenic Growth in Arabidopsis}

\author{
Geonhee Hwang ${ }^{1 \dagger}$, Jia-Ying Zhu ${ }^{2 \dagger}$, Young K. Lee ${ }^{3,4 t}$, Sara Kim ${ }^{1}$, Thom T. Nguyen', \\ Jungmook Kim ${ }^{1}$ and Eunkyoo $\mathrm{Oh}^{1 *}$
}

\begin{abstract}
${ }^{1}$ Department of Bioenergy Science and Technology, Chonnam National University, Gwangju, South Korea, ${ }^{2}$ Department of Plant Biology, Carnegie Institution for Science, Stanford, CA, United States, ${ }^{3}$ Cold Spring Harbor Laboratory, Cold Spring Harbor, NY, United States, ${ }^{4}$ Division of Biological Sciences and Institute for Basic Science, Wonkwang University, Iksan, South Korea
\end{abstract}

Arabidopsis plants adapt to high ambient temperature by a suite of morphological changes including elongation of hypocotyls and petioles and leaf hyponastic growth. These morphological changes are collectively called thermomorphogenesis and are believed to increase leaf cooling capacity by enhancing transpiration efficiency, thereby increasing tolerance to heat stress. The bHLH transcription factor PHYTOCHROME INTERACTING FACTOR4 (PIF4) has been identified as a major regulator of thermomorphogenic growth. Here, we show that PIF4 promotes the expression of two homologous genes LONGIFOLIA1 (LNG1) and LONGIFOLIA2 (LNG2) that have been reported to regulate leaf morphology. ChIP-Seq analyses and ChIP assays showed that PIF4 directly binds to the promoters of both LNG1 and LNG2. The expression of $L N G 1$ and $L N G 2$ is induced by high temperature in wild type plants. However, the high temperature activation of $L N G 1$ and $L N G 2$ is compromised in the pif4 mutant, indicating that PIF4 directly regulates $L N G 1$ and $L N G 2$ expression in response to high ambient temperatures. We further show that the activities of LNGs support thermomorphogenic growth. The expression of auxin biosynthetic and responsive genes is decreased in the Ing quadruple mutant, implying that LNGs promote thermomorphogenic growth by activating the auxin pathway. Together, our results demonstrate that LNG1 and LNG2 are directly regulated by PIF4 and are new components for the regulation of thermomorphogenesis.

Keywords: Arabidopsis, high temperature stress, thermomorphogenesis, PIF4, LNG, gene expression, ChIP

\section{INTRODUCTION}

Increases in ambient temperature have profound and mostly negative effects on plant growth and development. As a consequence, the phenology and distribution of crop and wild plants are already being affected by climate change (Willis et al., 2008). Plants have evolved various developmental responses to adapt to high temperature stresses One such response is acceleration of the vegetative to reproductive transition (flowering) (Balasubramanian et al., 2006), which increases species survival under high temperature stress, as dormant seeds have greater tolerance 
of stress than growing plants. Various morphological changes can occur under high temperature conditions: stem elongation, leaf hyponastic growth, and decrease in leaf thickness (Quint et al., 2016). These morphological changes are collectively described as thermomorphogenic responses, and are assumed to increase plant cooling capacity by enhancing leaf transpiration efficiency, thereby helping plants survive under high temperature stress (Crawford et al., 2012). Support for this belief has been obtained recently in a study that showed thermomorphogenic growth enhanced plant tolerance to heat stress (Zhu et al., 2016). Our understanding of thermomorphogenesis is still incomplete particularly with regard to the molecular mechanisms. Elucidation of the mechanisms of thermomorphogenesis will be of value for developing heat-tolerant crops, which may be critical in future for food security in a warming climate.

In Arabidopsis, the bHLH transcription factor PHYTOCHROME INTERACTING FACTOR4 (PIF4) is a key regulator of thermomorphogenesis (Koini et al., 2009; Choi and Oh, 2016; Quint et al., 2016). PIF4 was first identified as a phytochrome interacting factor that negatively regulates a light signaling pathway (Huq and Quail, 2002). The role of PIF4 in thermomorphogenesis was later indicated by the thermoinsensitive growth phenotypes of a pif4 mutant (Koini et al., 2009). High temperatures reduce the activity of EARLY FLOWERING 3 (ELF3), a transcriptional repressor of PIF4; this reduction in ELF3 activity results in transcriptional activation of PIF4 (Mizuno et al., 2014; Box et al., 2015). The increase in PIF4 at high temperature causes increased binding to the promoters of the auxin biosynthetic genes YUC8 and TAA1 and of the auxin responsive genes IAA19 and IAA29, which directly activates their expression (Koini et al., 2009; Franklin et al., 2011; Oh et al., 2012; Sun et al., 2012). The resulting activated auxin biosynthesis/signaling pathway induces thermomorphogenic alterations including hypocotyl and petiole elongation (Franklin et al., 2011; Sun et al., 2012). In addition to auxin, plant hormones such as brassinosteroid and gibberellin have been reported to be required for thermomorphogenic growth (Gray et al., 1998; Stavang et al., 2009). It was recently shown that blue and UV-B light suppresses thermomorphogenesis by inhibiting PIF4 activity via multiple mechanisms (Ma et al., 2016; Pedmale et al., 2016; Hayes et al., 2017). The circadian clock has also been found to participate in thermomorphogenesis through the action of the evening-expressed circadian clock protein TOC1 (Zhu et al., 2016). TOC1 directly interacts with PIF4 and represses its activity, thereby suppressing thermomorphogenic growth during the evening (Zhu et al., 2016).

The homologous proteins LONGIFOLIA1 (LNG1) and LONGIFOLIA2 (LNG2) regulate leaf morphology in Arabidopsis (Lee et al., 2006). The LNG proteins positively promote longitudinal polar cell elongation; this role is exemplified by the $\operatorname{lng}$ gain-of-function mutant $(\operatorname{lng}-D)$, which displays extremely long leaf blades, elongated floral organs, and elongated siliques (Lee et al., 2006). In contrast, $\operatorname{lng} 1 ; \ln g 2$ double mutants have short petioles and leaf blades (Lee et al., 2006). Consistent with their physiological functions, LNG1 and LNG2 genes are expressed in various organs including the petioles, leaf blades, flowers, and roots (Lee et al., 2006). The LNGs encode plant specific proteins without any known functional domains. The LNG proteins were detected in both the cytosol and nucleus (Lee et al., 2006), although the molecular mechanisms of LNGmediated longitudinal polar cell elongation are still unknown. LNG gene family was identified in the plant species including in moss, Physcomitrella patens, from the database ${ }^{1}$ (TelloRuiz et al., 2016). The Arabidopsis genome contains two other LNG homologous proteins, LNG3 (AGI:At1g74160) and LNG4 (AGI:At1g18620). In addition to the regulation of longitudinal polar cell elongation, LNG proteins have been shown to be involved in microtubule organization through the recruitment of TONNEAU1 (TON1) to the cytoskeleton (Drevensek et al., 2012).

Here, we show that PIF4 directly binds to the promoters of LNG1 and LNG2. qRT-PCR analyses revealed that expression of LNG1 and LNG2 was temperature-regulated by PIF4 dependent manner. We further show that LNG proteins are required for the high temperature activation of the auxin biosynthetic gene YUC8 and auxin responsive gene IAA29. Thermomorphogenic growth is compromised in the lng quadruple (lngq) mutant that carries mutations in all four $L N G$ genes. Together, our results demonstrate that PIF4 transcriptionally activates LNG1 and LNG2 in response to high temperature, and thereby induces thermomorphogenic growth.

\section{MATERIALS AND METHODS}

\section{Plant Materials and Growth Conditions}

Arabidopsis thaliana plants were grown in a greenhouse with $16 \mathrm{~h}$ light $/ 8 \mathrm{~h}$ dark cycles at $22-24^{\circ} \mathrm{C}$ for general growth and seed harvesting. All $A$. thaliana plants used in this study belonged to the Col- 0 ecotype background. The PIF4p::PIF4-MYC transgenic plants used in the ChIP assays were described previously (Oh et al., 2012). The lngq plants were generated by crossing the single lng mutants lng1-3 (Salk_135586), lng2-1 (Salk_067658), Ing3-2 (Salk_068678), and $\operatorname{lng4-1}$ (Salk_144569).

\section{Hypocotyl Length Measurement}

Seeds were sterilized in $70 \%(\mathrm{v} / \mathrm{v})$ ethanol and $0.01 \%(\mathrm{v} / \mathrm{v})$ Triton X-100 and then plated on MS medium (Duchefa) supplemented with $0.75 \%$ phyto agar (Duchefa). After 3 days of stratification at $4^{\circ} \mathrm{C}$, the plates were placed under white light for $6 \mathrm{~h}$ to promote seed germination and incubated at $20^{\circ} \mathrm{C}$ under $24 \mathrm{~h}$ light conditions (light intensity: $30 \mu \mathrm{mol} \mathrm{m}^{-2} \mathrm{~s}^{-1}$ ) for 7 days or incubated at $20^{\circ} \mathrm{C}$ for 4 days followed by incubation at $28^{\circ} \mathrm{C}$ for 3 days. Seven-day-old seedlings were photocopied and hypocotyl lengths were measured using ImageJ software ${ }^{2}$.

\section{Petiole Length Measurement}

WT and $\ln g q$ seedlings were grown under white light at $20^{\circ} \mathrm{C}$ for 2 weeks or at $20^{\circ} \mathrm{C}$ for 1 week followed by incubation at $28^{\circ} \mathrm{C}$ for 1 week. Two-week-old plants were photocopied and petiole

\footnotetext{
${ }^{1}$ http://www.gramene.org/

${ }^{2}$ http://rsb.info.nih.gov/ij
} 

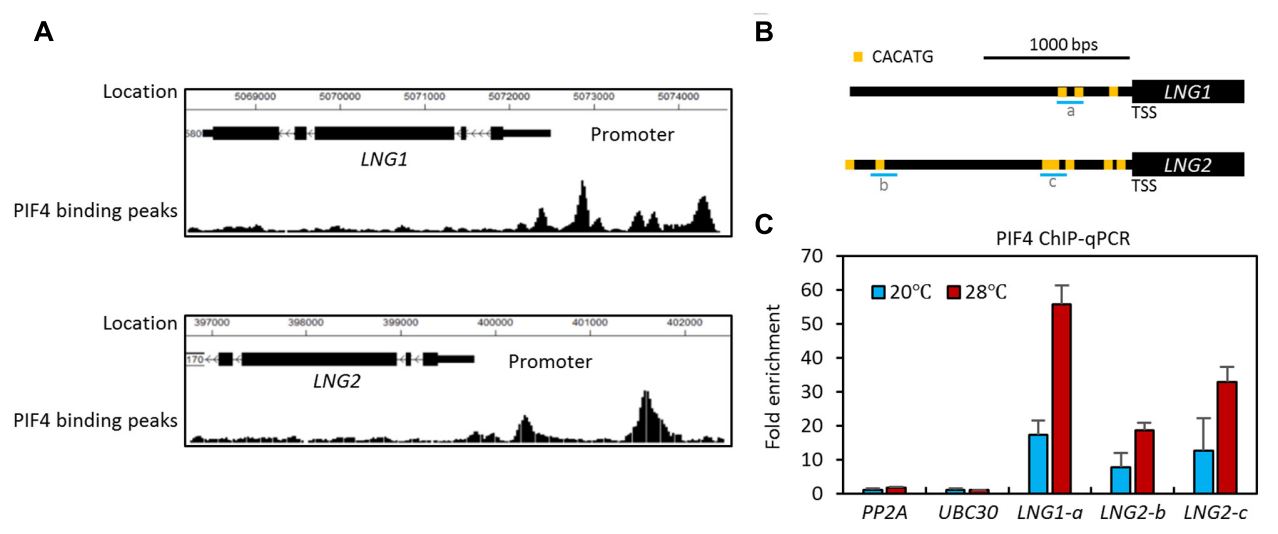

FIGURE 1 | PHYTOCHROME INTERACTING FACTOR4 directly binds to the promoters of LNG1 and LNG2. (A) Previous ChIP-Seg analyses (Oh et al., 2012) showing the PIF4 binding peaks around the promoters of LNG1 and LNG2. (B) A diagram of the LNG1 and LNG2 promoters showing the positions of PBE (PIF4 Binding E-box: CATGTG) motifs. a, b, and, c indicate the ChIP amplicons in the ChIP assays in (C). (C) ChIP-quantitative PCR assays of PIF4 binding to LNG1 and LNG2 promoters. Five-day-old WT and PIF4p::PIF4-MYC transgenic seedlings were grown at $20^{\circ} \mathrm{C}$, then switched to $28^{\circ} \mathrm{C}$ for $4 \mathrm{~h}$ or kept at $20^{\circ} \mathrm{C}$; the seedlings were then harvested for ChIP assays using an anti-MYC antibody. Enrichment of DNA was calculated as the ratio between PIF4p::PIF4-MYC and WT control, normalized to that of the PP2A coding region as an internal reference. Error bars indicate standard deviation (SD, $n=3)$.

lengths (from the base of leaf blade to the point of attachment to hypocotyl/shoot apical meristem) were measured using ImageJ software ${ }^{3}$.

\section{qRT-PCR Gene Expression Analysis}

Seedlings were grown at $20^{\circ} \mathrm{C}$ in $12 \mathrm{~h}$ light $/ 12 \mathrm{~h}$ dark conditions for 4 days and then transferred to $24 \mathrm{~h}$ light conditions on the 5 th day. The seedlings were then incubated at $20^{\circ} \mathrm{C}$ for $24 \mathrm{~h}$ or subjected to $28^{\circ} \mathrm{C}$ during ZT20 to ZT24, before harvesting for total RNA extraction. Total RNA was extracted from the seedlings using the MiniBEST Plant RNA extraction kit (TaKaRa). M-MLV reverse transcriptase (Fermentas) was used to synthesize cDNA from the RNA. Quantitative real-time PCR (qRT-PCR) was performed using the CFX96 Real-Time PCR detection system (Bio-Rad) and the EvaGreen master mix (Solgent). Gene expression levels were normalized to that of the SERINE/THREONINE PROTEIN PHOSPHATASE 2A (PP2A) gene and are shown relative to the expression levels in wild type. Gene specific primers are listed in Supplementary Table S1.

\section{Chromatin Immunoprecipitation (ChIP) Assays}

Chromatin Immunoprecipitation assays were performed as previously described (Oh et al., 2014). Seven-day-old PIF4p::PIF4-MYC seedlings were placed in $1 \%$ formaldehyde under vacuum for $20 \mathrm{~min}$ to produce protein-DNA crosslinks. Chromatin was recovered from the plant cells and immunoprecipitated as described [21]; the chromatin was resuspended in lysis buffer $(50 \mathrm{mM}$ Tris- $\mathrm{HCl} \mathrm{pH} \mathrm{8.0,10} \mathrm{mM}$ EDTA, $200 \mathrm{mM} \mathrm{NaCl}, 0.5 \%$ Triton X-100, $1 \mathrm{mM}$ PMSF) and sheared by sonication to reduce the average DNA fragment size to around 300 to 500 bps. The sonicated chromatin complex was then immunoprecipitated by an anti-MYC antibody (Cell

${ }^{3}$ http://rsb.info.nih.gov/ij
Signaling Technology) bound to protein A agarose beads (Millipore). The beads were washed with low-salt buffer $(50 \mathrm{mM}$ Tris- $\mathrm{HCl}$ at $\mathrm{pH}$ 8.0, $2 \mathrm{mM}$ EDTA, $150 \mathrm{mM} \mathrm{NaCl}, 0.5 \%$ Triton $\mathrm{X}-100)$, high-salt buffer $(50 \mathrm{mM}$ Tris- $\mathrm{HCl}$ at $\mathrm{pH} 8.0,2 \mathrm{mM}$ EDTA, $500 \mathrm{mM} \mathrm{NaCl}, 0.5 \%$ Triton X-100), LiCl buffer (10 mM Tris- $\mathrm{HCl}$ at $\mathrm{pH} 8.0,1 \mathrm{mM}$ EDTA, $0.25 \mathrm{M} \mathrm{LiCl}, 0.5 \% \mathrm{NP}-40$, $0.5 \%$ deoxycholate), and TE buffer (10 mM Tris- $\mathrm{HCl}$ at $\mathrm{pH} 8.0$, $1 \mathrm{mM}$ EDTA) and eluted with elution buffer (1\% SDS, $0.1 \mathrm{M}$ $\mathrm{NaHCO}_{3}$ ). The PIF4-MYC-bound DNA fragments were purified using a PCR purification kit (Thermo Scientific) and analyzed by ChIP-qPCR. The enrichment of DNA was normalized to that of PP2A. Primers for ChIP-qPCR are listed in Supplementary Table S1.

\section{Protein Extraction and Western Blot Analysis}

Wild type and $\operatorname{lng} q$ mutant seedlings were grown in the same conditions as for the qRT-PCR tests. Total proteins were extracted with $2 \mathrm{x}$ protein extraction buffer $(100 \mathrm{mM}$ Tris- $\mathrm{HCl}$, pH 6.8, 25\% glycerol, 2\% SDS, 0.01\% bromophenol blue, with $\beta$-mercaptoethanol added to $10 \%$ before use). Western blot analysis was performed to determine endogenous PIF4 levels using anti-PIF4 antibody (Agrisera, AS16 3157).

\section{RESULTS AND DISCUSSION}

\section{PIF4 Directly Binds to the Promoters of LNG1 and LNG2}

Our previous ChIP-Seq analyses identified LNG1 and LNG2 as PIF4 target genes (Oh et al., 2012). As shown in Figure 1A, there are several PIF4 binding peaks in the promoters of both LNG1 and LNG2, indicating that PIF4 directly binds to the promoter of these genes. In addition, LNG1 was identified as a PIF3 target gene and both LNG1 and LNG2 were identified 

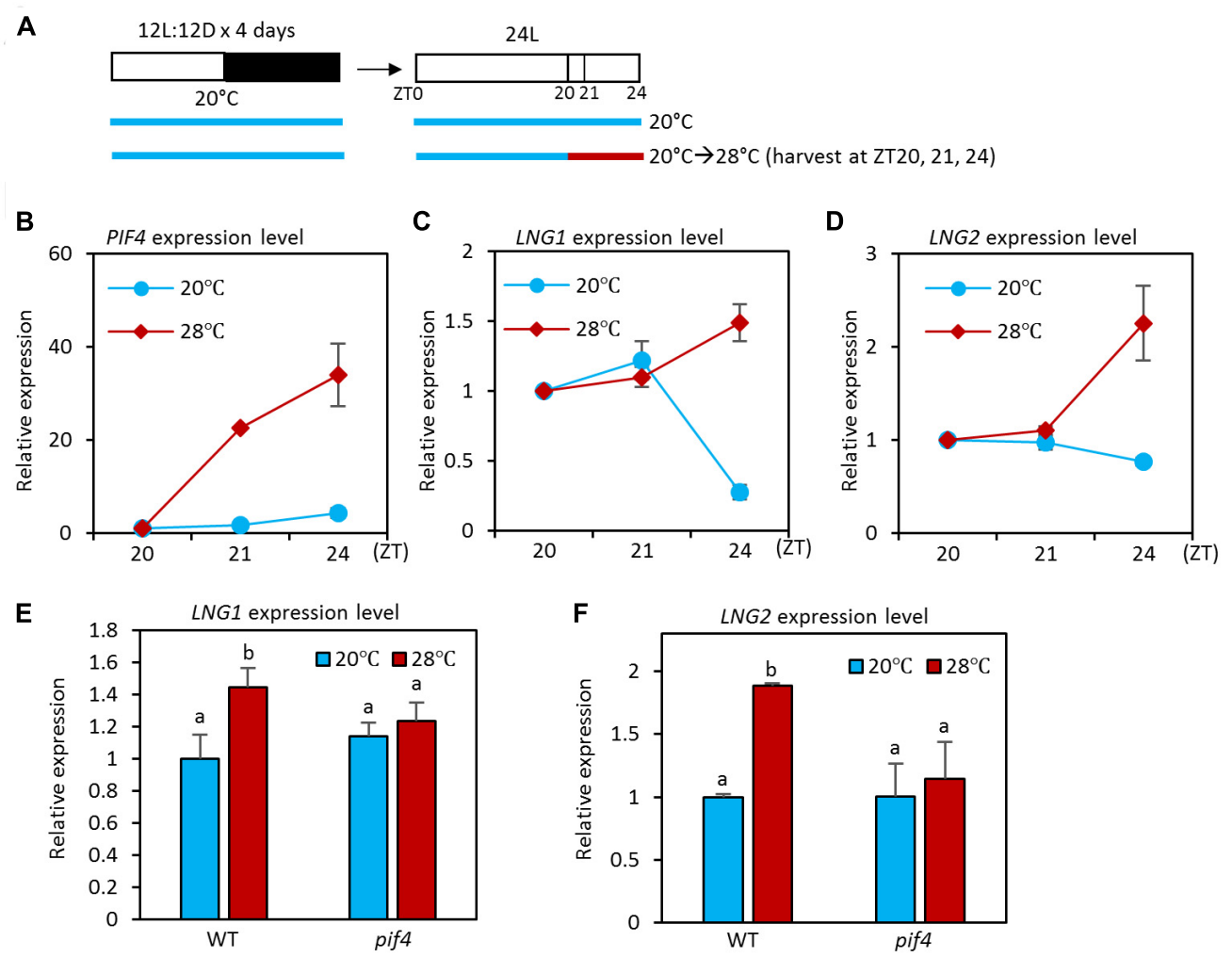

FIGURE 2 | High temperature activates the expression of LNG1 and LNG2 in a PIF4 dependent manner. (A) Diagram showing plant growth conditions used for the qRT-PCR analyses in (B) and (F). Seedlings were maintained under $12 \mathrm{~h}$ light/12 h dark conditions at $20^{\circ} \mathrm{C}$ for 4 days, and then transferred to $24 \mathrm{~h}$ light conditions. The seedlings were then exposed for 1 or $4 \mathrm{~h}$ to high temperature $\left(28^{\circ} \mathrm{C}\right)$ from $\mathrm{ZT} 20$ and harvested for RNA extraction. (B-D) The qRT-PCR analysis of the expression levels of PIF4, LNG1, and LNG2 in WT seedlings under the indicated growth conditions. Gene expression levels were normalized to PP2A and presented as values relative to those of the $\mathrm{WT}$ seedlings at $20^{\circ} \mathrm{C}$ at ZT20. Error bars indicate standard deviation $(\mathrm{SD}, n=3)$. (E,F) The qRT-PCR analysis of the expression levels of LNG1 and LNG2. WT and pif4 mutant seedlings were exposed for $4 \mathrm{~h}$ to high temperature $\left(28^{\circ} \mathrm{C}\right)$ from $\mathrm{ZT} 20$ or kept at $20^{\circ} \mathrm{C}$. Error bars indicate SD $(n=3)$. Different letters above each bar indicate statistically significant differences (ANOVA and Tukey's HSD; $P<0.05$ ).

as PIF5 target genes by PIF3 and PIF5 ChIP-Seq analyses, respectively (Hornitschek et al., 2012; Zhang et al., 2013). LNG3 and LNG4 have also been identified as PIF1 and PIF4 target genes (Supplementary Figure S1A; Oh et al., 2014; Pfeiffer et al., 2014). To confirm the results of the previous large scale experiments, we performed ChIP assays with transgenic plants expressing a PIF4-Myc fusion protein under a PIF4 promoter (PIF4p::PIF4-MYC). To examine the effect of high temperature, we included seedlings exposed for $4 \mathrm{~h}$ to high temperature. The ChIP assays showed that PIF4 directly binds to the promoter of LNG1 (about -400 bps from the transcription start sequence, TSS) and the promoter of LNG2 (about -600 bps and -1700 bps from the TSS) (Figures 1B,C). These results are consistent with those of the previous PIF4 ChIPSeq analyses. PIF4 appears to bind to these promoters through the E-box motif variant (CACATG), which has previously been shown to be a PIF4 binding motif (Oh et al., 2012; Zhang et al., 2013). Interestingly, PIF4 binding to these promoters was increased by the high temperature treatment (Figure 1C); this is consistent with previous studies showing that PIF4 protein activity is increased at elevated temperatures (Mizuno et al., 2014; Zhu et al., 2016). Our results indicate that PIF4 directly binds to the promoters of both LNG1 and LNG2, and presumably regulates their expression in a temperature dependent manner.

\section{The Expression of LNG1 and LNG2 Is Increased by High Temperature}

PHYTOCHROME INTERACTING FACTOR4 is a key regulator of thermoresponsive growth and thermoregulation of expression of various genes (Choi and Oh, 2016; Quint et al., 2016). In addition, PIF4 activity increases as ambient temperature is elevated (Koini et al., 2009). Since the PIF4 transcription factor activates transcription and binds directly to LNG1 and LNG2 promoters (Zhu et al., 2016) and the binding is enhanced at high temperatures (Figure 1), it is highly likely that the expression of LNG1 and LNG2 is also temperatureregulated. To test whether this is the case, we used qRTPCR to determine the transcriptional responses of LNG1 and LNG2 to an increase in ambient temperature. For the qRTPCR analyses, seedlings were grown under $12 \mathrm{~h}$ light/12 h dark conditions at $20^{\circ} \mathrm{C}$ for 4 days, and then transferred to $24 \mathrm{~h}$ light conditions (Figure 2A). The seedlings were exposed 


\section{A}

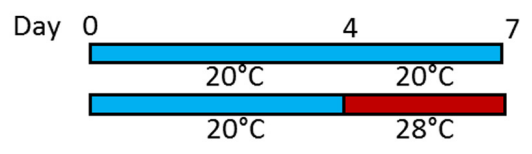

B

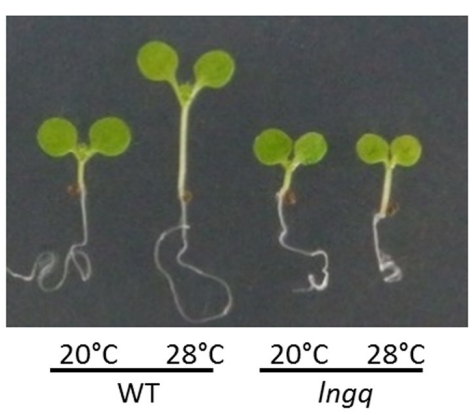

D

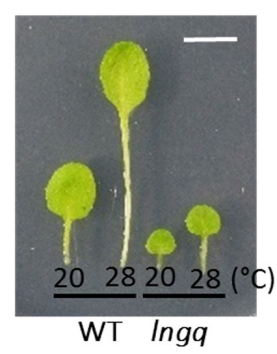

E

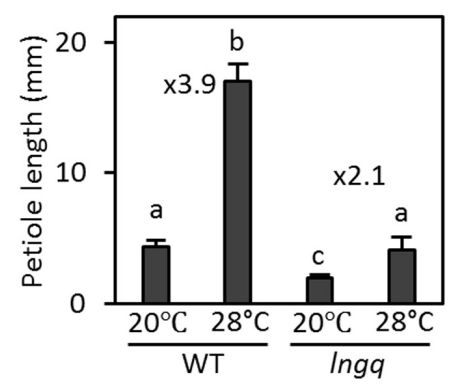

C

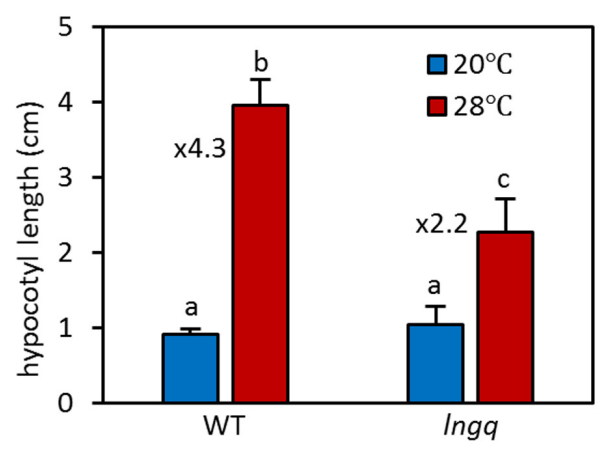

F

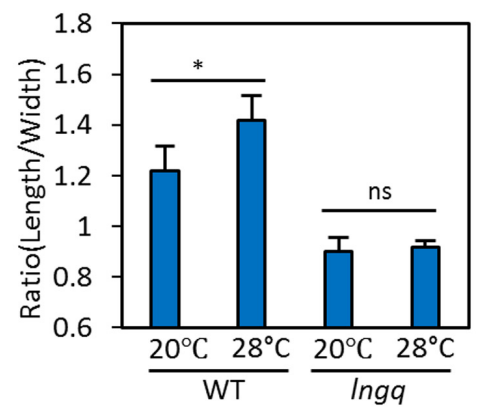

FIGURE 3 | LONGIFOLIA activities are required for thermomorphogenic growth. (A) Diagram showing plant growth conditions for hypocotyl length measurements. WT and Ingq seedlings were grown at $20^{\circ} \mathrm{C}$ for 7 days or grown at $20^{\circ} \mathrm{C}$ for 4 days followed by incubation at $28^{\circ} \mathrm{C}$ for 3 days before harvesting for hypocotyl length measurements. (B) Representative seedlings grown under the conditions described in (A). (C) Average hypocotyl lengths of WT and Ingq seedlings grown under the conditions described in (A). Error bars indicate standard deviation (SD, $n=10$ plants). Numbers indicate ratios of hypocotyl lengths (28 $\left.{ }^{\circ} \mathrm{C} / 20^{\circ} \mathrm{C}\right)$. Different letters above each bar indicate statistically significant differences (ANOVA and Tukey's HSD; $P<0.05$ ). (D) Representative leaf blades and petioles of wild type and Ingq plants grown at $20^{\circ} \mathrm{C}$ or $28^{\circ} \mathrm{C}$ for 2 weeks. Bar indicates $5 \mathrm{~mm}$. (E) Average petiole lengths of WT and Ingq plants grown at two different temperatures. Error bars indicate SD ( $n=20$ petioles). Numbers indicate ratios of petiole lengths $\left(28^{\circ} \mathrm{C} / 20^{\circ} \mathrm{C}\right)$. Different letters above each bar indicate statistically significant differences (ANOVA and Tukey's HSD; $P<0.05$ ). (F) Average ratio of the leaf length to width of plants grown at $20^{\circ} \mathrm{C}$ or $28^{\circ} \mathrm{C}$. The third and fourth leaves were analyzed. Error bars indicate SD ( $n=10$ leaves). ${ }^{*} P<0.05$ (Student's $t$-test) and ns indicates not significant.

for 1 or $4 \mathrm{~h}$ to a temperature of $28^{\circ} \mathrm{C}$ at ZT20 at which time the plants are highly sensitive to high temperature due to the elevated PIF4 activity (Mizuno et al., 2014). The qRTPCR analyses showed that expression of both LNG1 and LNG2 was not significantly affected by $1 \mathrm{~h}$ of high temperature treatment (Figures 2C,D). However, while LNG1 expression was decreased at ZT24 in the seedlings at $20^{\circ} \mathrm{C}$, it was slightly increased in the seedlings at $28^{\circ} \mathrm{C}$ (Figures 2C,D). LNG2 expression was also induced by $4 \mathrm{~h}$ of high temperature treatment. In contrast, PIF4 expression was rapidly induced in response to high temperature within $1 \mathrm{~h}$ (Figure 2B). The rapid activation of PIF4 before LNGs induction suggests that PIF4 mediates the high temperature-induced LNG1 and LNG2 expression.

\section{PIF4 Mediates the High Temperature Activation of LNG1 and LNG2 Expression}

Next, we examined whether high temperature activation of $L N G 1$ and LNG2 requires PIF4 activity. To perform this analysis, we measured the expression of LNG1 and LNG2 in wild type and pif4 mutant grown under normal conditions or at $28^{\circ} \mathrm{C}$ for $4 \mathrm{~h}$ (Figure 2A). Compared to wild type plants, expression of LNG1 and LNG2 was not significantly altered by high temperature in the pif4 mutant (Figures 2E,F), suggesting that PIF4 mediates the high temperature activation of LNG1 and LNG2 expression. Since the PIF4 binding to the LNG1 and LNG2 promoters is increased at high temperatures (Figure 1C), these results support our hypothesis that the elevation in the ambient temperature increases PIF4 activity and binding to the promoters of LNG1 and $L N G 2$, which leads to the transcriptional activation of $L N G 1$ and LNG2.

However, LNG1 and LNG2 expression was not significantly altered in the pif4 mutant at $20^{\circ} \mathrm{C}$. Since other PIFs (including PIF1, PIF3, and PIF5) have also been shown to directly bind to LNG1 and LNG2 promoters, it is possible that the remaining PIFs redundantly regulate $L N G 1$ and $L N G 2$ in the pif4 mutant at $20^{\circ} \mathrm{C}$. In support of this possibility, previous microarray analyses with a pif4;pif5 double mutant showed that both LNG1 and LNG2 
A

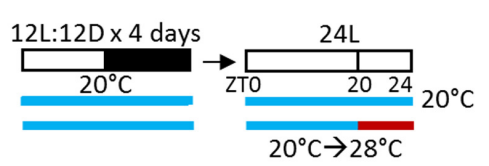

B

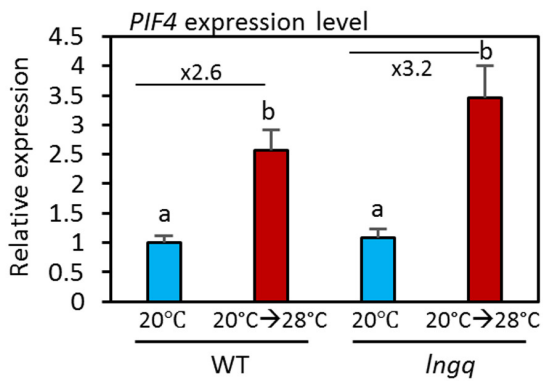

C

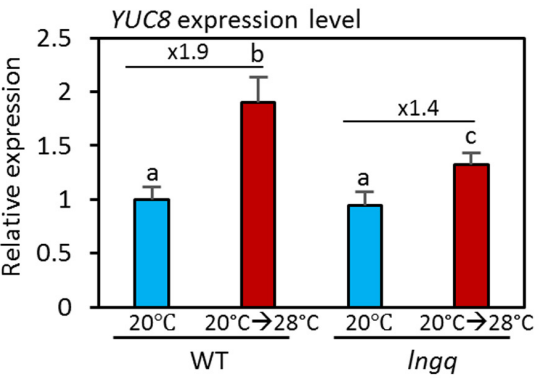

D

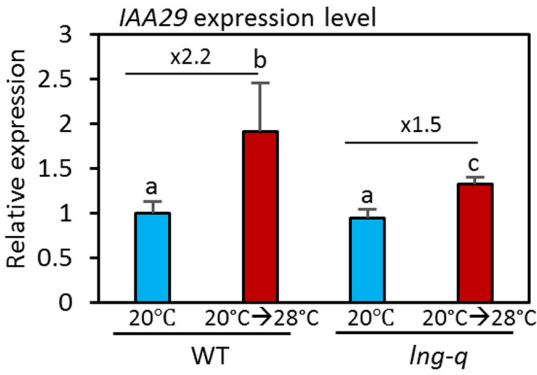

E

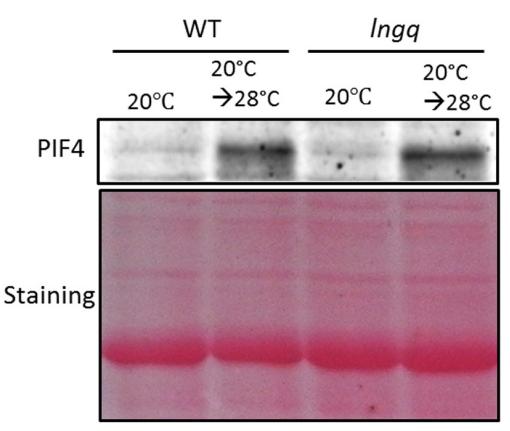

$\mathbf{F}$

High temperature

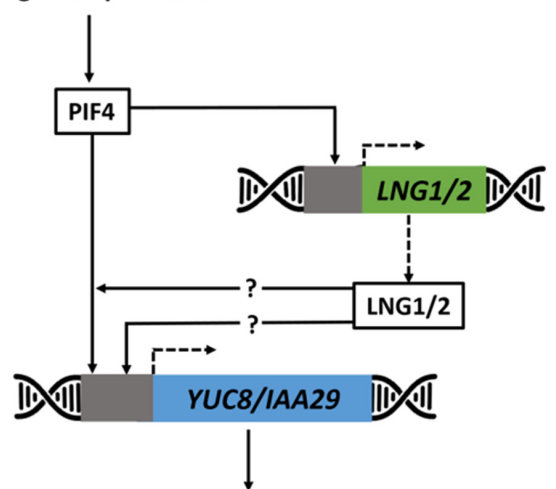

Auxin biosynthesis \& signaling

Thermomorphogenic growth

FIGURE 4 | The expression of YUC8 and IAA29 is hyposensitive to high temperature in Ingq seedlings. (A) Diagram showing plant growth conditions used for the qRT-PCR analyses in (B-D). Seedlings were maintained under $12 \mathrm{~h}$ light/12 $\mathrm{h}$ dark at $20^{\circ} \mathrm{C}$ for 4 days, and then transferred to $24 \mathrm{~h}$ light conditions. The seedlings were then exposed for $4 \mathrm{~h}$ to high temperature $\left(28^{\circ} \mathrm{C}\right)$ at ZT20 and harvested for RNA extraction. (B-D) The qRT-PCR analysis of the expression level of YUC8 and IAA29. Gene expression levels were normalized to PP2A and presented as values relative to those of the WT seedlings at $20^{\circ} \mathrm{C}$. Error bars indicate standard deviation (SD, $n=3)$. Numbers indicate ratios of the expression levels $\left(28^{\circ} \mathrm{C} / 20^{\circ} \mathrm{C}\right)$. Different letters above each bar indicate statistically significant differences (ANOVA and Tukey's HSD; $P<0.05$ ). (E) Western blotting with anti-PIF4 antibody showed that PIF4 protein levels were increased by high temperatures in both wild type and Ingq seedlings. Total protein was extracted from the seedlings grown in the conditions described in (A). Equal loading of samples is shown by Ponceau S staining. (F) A hypothetical model depicting PIF4-LNGs-mediated thermomorphogenic growth. At elevated temperatures, PIF4 transcription factor binds to the promoters of LNG1 and LNG2 as well as auxin-related genes (YUC8 and IAA29), and activate their expression. The increased LNG proteins further activate the expression of YUC8 and IAA29 through unknown mechanisms. The resulting increased auxin biosynthesis and signaling induce thermomorphogenic growth.

expression is lower in the pif4;pif5 double mutant than in the wild type at normal temperatures (Supplementary Figure S2) (Hornitschek et al., 2012).

\section{LNGs Are Required for the Thermoresponsive Growth}

Since both LNG1 and LNG2 are directly regulated by PIF4 and high temperature, it is likely that these LNG proteins are involved in PIF4-mediated developmental responses including thermomorphogenesis. Therefore, we examined whether the
LNG proteins play a role in thermomorphogenesis. To perform this analysis, wild type and $\operatorname{lng}$ quadruple mutant ( $\operatorname{lng} 1 ; \operatorname{lng} 2 ; \ln 93 ; \ln g 4, \ln g q)$ seedlings were grown at $20^{\circ} \mathrm{C}$ for 7 days or at $20^{\circ} \mathrm{C}$ for 4 days followed by $28^{\circ} \mathrm{C}$ incubation for 3 days before harvesting for hypocotyl measurement (Figure 3A). We analyzed the $\operatorname{lng} q$ mutant in order to completely remove any residual activities of other LNG proteins because LNG3 and LNG4 are also direct target genes of PIF4 (Supplementary Figures $\mathrm{S} 1 \mathrm{~A}, \mathrm{~B})$, and $L N G 4$ expression is increased at high temperatures (Supplementary Figure S1C). Under these growth conditions, 
hypocotyl elongation in wild type seedlings was strongly promoted by the high temperature $\left(28^{\circ} \mathrm{C}\right)$. The hypocotyls of wild type at $28^{\circ} \mathrm{C}$ were four times longer than those of wild type seedlings grown at $20^{\circ} \mathrm{C}$ (Figures 3B,C). However, the hypocotyl length of $\operatorname{lng} q$ seedlings at $28^{\circ} \mathrm{C}$ was only about twofold longer than that of those grown at $20^{\circ} \mathrm{C}$ (Figures $3 \mathrm{~B}, \mathrm{C}$ ), indicating that hypocotyl growth in $\ln g q$ seedlings is less sensitive to high temperature than in wild type seedlings. In addition to the hypocotyls, leaf petiole elongation is also promoted by high temperature, which is mediated by PIF4 (Koini et al., 2009). The petiole elongation response to high temperature was also attenuated in the lngq plants, similar to the hypocotyl elongation (Figures 3D,E). These results suggest that PIF4 induces thermoresponsive growth by activating LNGs as well as auxin genes.

Previous studies showed that LNG1 and LNG2 promote longitudinal polar cell elongation, thereby determining leaf morphology (Lee et al., 2006). Since these LNGs are transcriptionally activated at high temperatures, it is likely that leaf morphology would be changed in response to an increase in ambient temperature. Indeed, wild type plants grown at $28^{\circ} \mathrm{C}$ have more elongated leaf blade (high ratio of leaf length to leaf width) than the same plants grown at $20^{\circ} \mathrm{C}$ (Figures 3D,F). In contrast to wild type, leaf shapes of $\ln g q$ mutant plants were not significantly altered by high temperature (Figure 3F), indicating that high temperatures promote the elongation of leaf blades through the transcriptional activation of $L N G s$.

\section{LNG Proteins Support Thermoregulation of Auxin Biosynthetic and Signaling Genes}

At high temperatures, PIF4 increases endogenous auxin levels by directly activating the auxin biosynthetic genes YUC8, TAA1, and $C Y P 79 B$. PIF4 also directly activates the expression of the auxin responsive genes IAA19 and IAA29 (Koini et al., 2009; Franklin et al., 2011; Oh et al., 2012; Sun et al., 2012). To examine the molecular mechanisms in which LNG proteins participate in the high temperature responses, we determined the expression levels of PIF4 and its target genes YUC8 and IAA29 in wild type and $\ln g q$ seedlings (Figure 4A). Previous studies showed that PIF4 is transcriptionally activated in response to high temperature (Koini et al., 2009; Yamashino et al., 2013). Consistent with this finding, the expression of PIF4 was found here to increase after a high temperature treatment in wild type seedlings (Figure 4B). PIF4 expression was also significantly upregulated by high temperature in $\operatorname{lng} q$ seedlings (Figure 4B), showing that the reduced thermomorphogenic growth of these seedlings is not caused by a reduced PIF4 level. Expression of the PIF4 target genes YUC8 and IAA29 expression was significantly elevated after high temperature in wild type seedlings (Figures 4C,D). However, the upregulation of YUC8 and IAA29 expression was not as great in $\operatorname{lngq}$ seedlings (Figures 4C,D). These results indicate that LNG proteins mediate in part the high temperature activation of auxin biosynthetic (YUC8) and responsive genes (IAA29). The expression patterns of YUC8 and IAA29 are consistent with the lack of hypocotyl elongation under high temperature conditions in $\operatorname{lng} q$ seedlings (Figure 3), suggesting that the reduced auxin biosynthesis contributes to the hypocotyl elongation defect of $\operatorname{lng} q$ seedlings grown at high temperatures.

\section{CONCLUSION}

Here, we demonstrated that the homologous proteins LNG1 and LNG2 regulate thermomorphogenic growth. At an elevated temperature, PIF4 transcription factor directly binds to the promoters of both LNG1 and LNG2 and activates their expression. The increased level of LNG proteins then induces thermomorphogenic growth including hypocotyl, petiole, and leaf blade elongation at least partly through up-regulation of auxin biosynthetic and responsive genes (YUC8 and IAA29). Since YUC8 and IAA29 are known to be directly regulated by PIF4, LNGs are likely to increase the PIF4 level to induce YUC8 and IAA29 expression. However, PIF4 mRNA expression and PIF4 protein levels were not significantly affected in $\ln g q$ seedlings (Figures $4 \mathrm{~B}, \mathrm{E}$ ), suggesting that LNGs activate PIF4 post-translationally either by promoting PIF4 binding to target DNAs or enhancing PIF4 transcription activity. In addition, PIF4 and LNGs appear to constitute a feed-forward loop because the PIF4-activated LNGs potentiate PIF4 activation of auxin pathway genes (YUC8 and IAA29). Such a feedforward loop may enable plants to rapidly respond to an ambient temperature increase (Figure $\mathbf{4 F}$ and Supplementary Figure S3).

It has previously been shown that the LNG proteins regulate microtubule organization by recruiting a centrosomal protein (Drevensek et al., 2012); however, the mechanism through which LNG proteins control gene expression remains to be elucidated. A previous study suggested that the elongated petioles and leaf elevation may potentially enhance leaf transpiration rates by increasing the diffusion of water vapor from stomata (Crawford et al., 2012). It would be also of interest to examine whether LNG-induced leaf morphological changes also contribute to enhanced leaf transpiration rates at high temperatures.

\section{AUTHOR CONTRIBUTIONS}

GH, J-YZ, YL, and EO designed research, analyzed data, wrote manuscript, assembled and edited figures. SK designed experiments, conducted research, analyzed data. TN conducted experiments. JK conducted research and analyzed data.

\section{ACKNOWLEDGMENTS}

Research was supported by a grant from the National Research Foundation of Korea (NRF) grant funded by Korea government (MSIP; Number NRF-2016R1C1B2008821), the Basic Research Laboratory program of the National Research Foundation funded by the Korean government 
(grant no. 2017R1A4A1015620), Chonnam National University (Grant number: 2016-2514), and Brain Pool Program through the Korean Federation of Science and Technology Societies (KOFST, 171S-4-3-1865) funded by the Ministry of Science, ICT and Future Planning.

\section{REFERENCES}

Balasubramanian, S., Sureshkumar, S., Lempe, J., and Weigel, D. (2006). Potent induction of Arabidopsis thaliana flowering by elevated growth temperature. PLoS Genet. 2:e106. doi: 10.1371/journal.pgen.0020106

Box, M. S., Huang, B. E., Domijan, M., Jaeger, K. E., Khattak, A. K., Yoo, S. J., et al. (2015). ELF3 controls thermoresponsive growth in Arabidopsis. Curr. Biol. 25, 194-199. doi: 10.1016/j.cub.2014.10.076

Choi, H., and Oh, E. (2016). PIF4 integrates multiple environmental and hormonal signals for plant growth regulation in Arabidopsis. Mol. Cells 39, 587-593. doi: 10.14348/molcells.2016.0126

Crawford, A. J., Mclachlan, D. H., Hetherington, A. M., and Franklin, K. A. (2012). High temperature exposure increases plant cooling capacity. Curr. Biol. 22, R396-R397. doi: 10.1016/j.cub.2012.03.044

Drevensek, S., Goussot, M., Duroc, Y., Christodoulidou, A., Steyaert, S., Schaefer, E., et al. (2012). The Arabidopsis TRM1-TON1 interaction reveals a recruitment network common to plant cortical microtubule arrays and eukaryotic centrosomes. Plant Cell 24, 178-191. doi: 10.1105/tpc.111.089748

Franklin, K. A., Lee, S. H., Patel, D., Kumar, S. V., Spartz, A. K., Gu, C., et al. (2011). Phytochrome-interacting factor 4 (PIF4) regulates auxin biosynthesis at high temperature. Proc. Natl. Acad. Sci. U.S.A. 108, 20231-20235. doi: 10.1073/pnas. 1110682108

Gray, W. M., Ostin, A., Sandberg, G., Romano, C. P., and Estelle, M. (1998). High temperature promotes auxin-mediated hypocotyl elongation in Arabidopsis. Proc. Natl. Acad. Sci. U.S.A. 95, 7197-7202. doi: 10.1073/pnas.95.12.7197

Hayes, S., Sharma, A., Fraser, D. P., Trevisan, M., Cragg-Barber, C. K., Tavridou, E., et al. (2017). UV-B perceived by the UVR8 photoreceptor inhibits plant thermomorphogenesis. Curr. Biol. 27, 120-127. doi: 10.1016/j.cub.2016.11.004

Hornitschek, P., Kohnen, M. V., Lorrain, S., Rougemont, J., Ljung, K., LopezVidriero, I., et al. (2012). Phytochrome interacting factors 4 and 5 control seedling growth in changing light conditions by directly controlling auxin signaling. Plant J. 71, 699-711. doi: 10.1111/j.1365-313X.2012.05033.x

Huq, E., and Quail, P. H. (2002). PIF4, a phytochrome-interacting bHLH factor, functions as a negative regulator of phytochrome B signaling in Arabidopsis. EMBO J. 21, 2441-2450. doi: 10.1093/emboj/21.10.2441

Koini, M. A., Alvey, L., Allen, T., Tilley, C. A., Harberd, N. P., Whitelam, G. C., et al. (2009). High temperature-mediated adaptations in plant architecture require the bHLH transcription factor PIF4. Curr. Biol. 19, 408-413. doi: 10.1016/j.cub. 2009.01.046

Lee, Y. K., Kim, G. T., Kim, I. J., Park, J., Kwak, S. S., Choi, G., et al. (2006). LONGIFOLIA1 and LONGIFOLIA2, two homologous genes, regulate longitudinal cell elongation in Arabidopsis. Development 133, 4305-4314. doi: 10.1242/dev.02604

Ma, D., Li, X., Guo, Y., Chu, J., Fang, S., Yan, C., et al. (2016). Cryptochrome 1 interacts with PIF4 to regulate high temperature-mediated hypocotyl elongation in response to blue light. Proc. Natl. Acad. Sci. U.S.A. 113, 224-229. doi: 10.1073/pnas.1511437113

Mizuno, T., Nomoto, Y., Oka, H., Kitayama, M., Takeuchi, A., Tsubouchi, M., et al. (2014). Ambient temperature signal feeds into the circadian clock transcriptional circuitry through the EC night-time repressor in Arabidopsis thaliana. Plant Cell Physiol. 55, 958-976. doi: 10.1093/pcp/pcu030

Oh, E., Zhu, J. Y., Bai, M. Y., Arenhart, R. A., Sun, Y., and Wang, Z. Y. (2014). Cell elongation is regulated through a central circuit of interacting transcription factors in the Arabidopsis hypocotyl. eLife 3:e03031. doi: 10.7554/eLife.03031

\section{SUPPLEMENTARY MATERIAL}

The Supplementary Material for this article can be found online at: http://journal.frontiersin.org/article/10.3389/fpls.2017.01320/ full\#supplementary-material

Oh, E., Zhu, J. Y., and Wang, Z. Y. (2012). Interaction between BZR1 and PIF4 integrates brassinosteroid and environmental responses. Nat. Cell Biol. 14, 802-809. doi: 10.1038/ncb2545

Pedmale, U. V., Huang, S. S., Zander, M., Cole, B. J., Hetzel, J., Ljung, K., et al. (2016). Cryptochromes interact directly with PIFs to control plant growth in limiting blue light. Cell 164, 233-245. doi: 10.1016/j.cell.2015. 12.018

Pfeiffer, A., Shi, H., Tepperman, J. M., Zhang, Y., and Quail, P. H. (2014). Combinatorial complexity in a transcriptionally centered signaling hub in Arabidopsis. Mol. Plant 7, 1598-1618. doi: 10.1093/mp/ssu087

Quint, M., Delker, C., Franklin, K. A., Wigge, P. A., Halliday, K. J., and Zanten, M. (2016). Molecular and genetic control of plant thermomorphogenesis. Nat. Plants 2:15190. doi: 10.1038/nplants.2015.190

Stavang, J. A., Gallego-Bartolome, J., Gomez, M. D., Yoshida, S., Asami, T., Olsen, J. E., et al. (2009). Hormonal regulation of temperature-induced growth in Arabidopsis. Plant J. 60, 589-601. doi: 10.1111/j.1365-313X.2009. 03983.x

Sun, J., Qi, L., Li, Y., Chu, J., and Li, C. (2012). PIF4-mediated activation of YUCCA8 expression integrates temperature into the auxin pathway in regulating Arabidopsis hypocotyl growth. PLoS Genet. 8:e1002594. doi: 10.1371/ journal.pgen.1002594

Tello-Ruiz, M. K., Stein, J., Wei, S., Youens-Clark, K., Jaiswal, P., and Ware, D. (2016). Gramene: a resource for comparative analysis of plants genomes and pathways. Methods Mol. Biol. 1374, 141-163. doi: 10.1007/978-1-49393167-5_7

Willis, C. G., Ruhfel, B., Primack, R. B., Miller-Rushing, A. J., and Davis, C. C. (2008). Phylogenetic patterns of species loss in Thoreau's woods are driven by climate change. Proc. Natl. Acad. Sci. U.S.A. 105, 17029-17033. doi: 10.1073/ pnas.0806446105

Yamashino, T., Nomoto, Y., Lorrain, S., Miyachi, M., Ito, S., Nakamichi, N., et al. (2013). Verification at the protein level of the PIF4-mediated external coincidence model for the temperature-adaptive photoperiodic control of plant growth in Arabidopsis thaliana. Plant Signal. Behav. 8:e23390. doi: 10.4161/psb. 23390

Zhang, Y., Mayba, O., Pfeiffer, A., Shi, H., Tepperman, J. M., Speed, T. P., et al. (2013). A quartet of PIF bHLH factors provides a transcriptionally centered signaling hub that regulates seedling morphogenesis through differential expression-patterning of shared target genes in Arabidopsis. PLoS Genet. 9:e1003244. doi: 10.1371/journal.pgen.1003244

Zhu, J. Y., Oh, E., Wang, T., and Wang, Z. Y. (2016). TOC1-PIF4 interaction mediates the circadian gating of thermoresponsive growth in Arabidopsis. Nat. Commun. 7:13692. doi: 10.1038/ncomms13692

Conflict of Interest Statement: The authors declare that the research was conducted in the absence of any commercial or financial relationships that could be construed as a potential conflict of interest.

Copyright (C) 2017 Hwang, Zhu, Lee, Kim, Nguyen, Kim and Oh. This is an openaccess article distributed under the terms of the Creative Commons Attribution License (CC BY). The use, distribution or reproduction in other forums is permitted, provided the original author(s) or licensor are credited and that the original publication in this journal is cited, in accordance with accepted academic practice. No use, distribution or reproduction is permitted which does not comply with these terms. 